Texte Metzler 27

$\sqrt{14}$ 
Peter Nusser

\section{Romane für die Unterschicht}

Groschenhefte und ihre Leser

5., mit einer erweiterten Bibliographie

und einem Nachwort versehene Auflage

J. B. Metzlersche Verlagsbuchhandlung 
Die in [ ] erscheinenden Zahlen verweisen auf die Anmerkungen.

1.- 3. Tausend März 1973

4.- 6. Tausend November 1973

7.- 9. Tausend September 1974

10.-11. Tausend Juli 1976

12.-13. Tausend Januar 1979

14.-15. Tausend Januar 1981

CIP-Kurztitelaufnahme der Deutschen Bibliothek

\section{Nusser, Peter:}

Romane für die Unterschicht: Groschenhefte

u. ihre Leser / Peter Nusser. - 5., mit e. erw.

Bibliogr. u. e. Nachw, vers. Aufl., 14.-15. Tsd. -

Stuttgart: Metzler, 1981.

(Texte Metzler; 27)

ISBN 978-3-476-00465-9

ISBN 978-3-476-00465-9

ISBN 978-3-476-03147-1 (eBook)

DOI 10.1007/978-3-476-03147-1

(C) Springer-Verlag GmbH Deutschland 1981

Ursprünglich erschienen bei J. B. Metzlersche Verlagsbuchhandlung und Carl Ernst Poeschel Verlag GmbH in Stuttgart 1973/81 


\section{Inhaltsverzeichnis}

1. Allgemeine Angaben zur Produktion und Konsumtion von Groschenromanen. Zielsetzung und Methode der Untersuchung . . . . . . .

2. Sozialbeziehungen, Orientierungsmuster, Sprachverhalten der Unterund Mittelschicht . . . . . . . . . . . . . . . . . . . . 12

2.1. Zum Begriff der ssozialen Schichts . . . . . . . . . . . . . . 12

2.2. Sozialbeziehungen der Unter- und Mittelschicht . . . . . . . . 14

2.2.1. Die Situation am Arbeitsplatz . . . . . . . . . . . . . 14

2 2... Primär- und Sekundärbeziehungen . . . . . . . . . . . 15

ż.z.3. Die personale Organisation . . . . . . . . . . . . . . 18

2.2.4. Erziehung . . . . . . . . . . . . . . . . . . . . . . 19

2.3. Orientierungsmuster der Unter- und Mittelschicht . . . . . . . 22

2.4. Das Sprachverhalten der Unter- und Mittelschicht . . . . . . . 24

3. Groschenromane in ihrer Beziehung zu den psychologisch und soziologisch erklärbaren Einstellungen ihrer Rezipienten . . . . . . . . . 27

3.1. Die Darstellung von Personen in Groschenromanen . . . . . . 27

3.1.1. Allgemeine Kennzeichen der Personendarstellung . . . . 27

3.1.2. Personendarstellung und psychologisch erklärbare Einstellungen der Leserzielgruppe . . . . . . . . . . . . . . 29

3.1.3. Personendarstellung im Frauenroman . . . . . . . . 32

3.1.3.1. Die äußere Erscheinung der Personen . . . . . . 32

3.1.3.2. Die inneren Qualitäten der Personen . . . . . . 34

3.1.3.2.1. Exkurs über die Wunschziele im Frauenroman . . . . . . . . . . . . 37

3.1.3.3. Die Personendarstellung im Frauenroman und die soziologisch erklärbaren Einstellungen der Leserzielgruppe . . . . . . . . . . . . . 45

3.1.4. Personendarstellung im Abenteuerroman . . . . . . . . 51

3.1.4.1. Die äußere Erscheinung der Personen . . . . . . 51

3.1.4.2. Die inneren Qualitäten der Personen . . . . . . 53

3.1.4.3. Die Personendarstellung im Abenteuerroman und die soziologisch erklärbaren Einstellungen der Leserzielgruppe . . . . . . . . . . . . . . . . . . 60

3.2. Gegenstände in Groschenromanen . . . . . . . . . . . . . . 66

3.2.1. Allgemeine Kennzeichen und Funktionen der dargestellten Gegenstände . . . . . . . . . . . . . . . . . . . . 66

3.2.2. Die allgemeinen Kennzeichen und Funktionen der dargestellten Gegenstände und psychologisch erklärbare Einstellungen der Leserzielgruppe . . . . . . . . . . . 68 
3.2.3. Inhaltliche Analyse häufig beschriebener Gegenstände . . 69

3.2.4. Dargestellte Gegenstände und soziologisch erklärbare Einstellungen der Leserzielgruppe . . . . . . . . . . . 74

3.3. Die Handlung in Groschenromanen . . . . . . . . . . . . . 76

3.3.1. Allgemeine Kennzeichen der Handlung . . . . . . . . . 77

3.3.1.1. Typische Handlungsmuster in Frauen- und Abenteuerromanen . . . . . . . . . . . . . . . . . 77

3.3.1.2. Die erzählerische Anordnung der Vorgänge in Frauen- und Abenteuerromanen . . . . . . . . 79

3.3.2. Die allgemeinen Kennzeichen der Handlung und psychologisch erklärbare Einstellungen der Leserzielgruppe . . . 81

3.3.3. Die allgemeinen Kennzeichen der Handlung und das Problem der Aggressivität . . . . . . . . . . . . . . . . 84

3.4. Die Sprache der Groschenromane . . . . . . . . . . . . . . 88

3.4.1. Quantitative Analyse der Sprache der Groschenromane (Wortschatz, Syntax). Beziehungen zum Sprachverhalten der Unterschicht . . . . . . . . . . . . . . . 88

3.4.2. Qualitative Analyse der Sprache der Groschenromane am Beispiel von Redensarten und Sentenzen. Beziehungen zum Sprachverhalten der Unterschicht . . . . . . . . . . 90

4. Interpretation der Ergebnisse . . . . . . . . . . . . . . . . . 97

5. Anmerkungen . . . . . . . . . . . . . . . . 103

6. Litcraturverzeichnis . . . . . . . . . . . . . . 112

7. Nachwort zur vierten Auflage . . . . . . . . . . . . 121

8. Nachwort zur fünften Auflage . . . . . . . . . . . 123 